\title{
SINTESA DAN KARAKTERISASI HIDROGEL SUPER ABSORBEN POLIMER (SAP) BERBASIS SELULOSA MENGGUNAKAN CROSSLINKING AGENT WATER-SOLUBLE CARBODIIMIDE (WSC)
}

\author{
Lik Anah ${ }^{1}$ dan Nuri Astrini \\ Pusat Penelitian Kimia - LIPI \\ Jl. Cisitu-Sangkuriang, Bandung 40135 \\ ${ }^{1}$ likanah@yahoo.com
}

Diterima : 26 Januari 2015, Revisi akhir : 20 April 2015, Disetujui terbit : 8 Mei 2015

\author{
SYNTHESIS AND CHARACTERIZATION OF HYDROGEL SUPER ABSORBENT \\ POLYMER (SAP) BASED ON CELLULOSE USING WATER SOLUBLE \\ CARBODIIMIDE (WSC) AS CROSSLINKING AGENT
}

\begin{abstract}
Carboxymethylcellulose (CMCNa), hydroxyethyl cellulose (HEC) were used as raw materials for synthesizing a superabsorbent polymer (SAP) hydrogel by solution polymerization techniques using of $2.5 \%$ water-soluble carbodiimide (WSC) as crosslinking agent and 1\% citric acid as catalysator. The ratio of CMCNa to HEC at $1: 1 ; 3: 1 ; 5: 1$ and $10: 1$ were used as variable of process. The effect of monomer concentration on water absorbency and water uptake was studied. The swelling test showed that the highest water retention capacity $(6.58 \mathrm{~g} / \mathrm{g})$ was reached at ratio CMCNa to HEC $=5: 1$ in 100 minutes and the deswelling test (61.47\%) was reached at ratio CMCNa to HEC = 5:1 in 120 minutes. PPA absorb hydrogel was used as standard with equilibrium swelling $123 \mathrm{~g} / \mathrm{g}$. The SAP hydrogel were characterized by infra red spectroscopy, and the result showed that there were some of structural changes in height of few bands of hydrophylic groups such as $=C-H$ at $2930 \mathrm{~cm}^{-1}, \mathrm{C}-\mathrm{H}$ antisym and sym at 2875 $\mathrm{cm}^{-1}, \mathrm{H}$-bonded-OH at $2375 \mathrm{~cm}^{-1}$, -COO-antisym at $1600 \mathrm{~cm}^{-1}$ whereas $\mathrm{C}-\mathrm{O}$ at $1025 \mathrm{~cm}^{-1}$.
\end{abstract}

Keywords: hydrogel, SAP, swelling, crosslinking, WSC

\begin{abstract}
ABSTRAK
Super Absorbent Polymer (SAP) hydrogel yang disintesa melalui proses polimerisasi Carboxymethylcellulose (CMCNa), Hydroxyethyl Cellulose (HEC) menggunakan Water-soluble Carbodiimide (WSC) sebagai crosslinking agent telah dilakukan melalui teknik polimerisasi larutan (solution polimerization techniques). Pada percobaan awal telah ditetapkan konsentrasi monomer sebagai variabel proses yaitu $\mathrm{CMCNa} / \mathrm{HEC}$ rasio $=1: 1,3: 1,5: 1,10: 1$ dan masing-masing rasio direaksikan dengan 2,5\% WSC dan $1 \%$ asam sitrat sebagai katalisator. Pengaruh konsentrasi monomer diiuji dari kemampuan hasil gel yang terbentuk dalam menyerap dan mengikat air (water uptake) yang divisualisasikan sebagai swelling dan deswelling ratio. Hasil uji swelling menunjukkan bahwa derajat swelling tertinggi dicapai pada rasio $\mathrm{CMCNa} / \mathrm{HEC}=5: 1$ dalam waktu 100 menit dengan derajat swelling $=6,58 \mathrm{~g} / \mathrm{g}$. Hidrogel PPA absorb komersial digunakan sebagai standar pembanding dengan derajat swelling $123 \mathrm{~g} / \mathrm{g}$. Hasil uji deswelling menunjukkan bahwa persentase retensi air dalam gel adalah $61,47 \%$ untuk rasio $\mathrm{CMCNa} / \mathrm{HEC}=5: 1$ pada 120 menit. Hasil karakterisasi gugus fungsi melalui analisis FTIR menunjukkan bahwa ada perbedaan nyata antara selulosa awal dengan selulosa yang direaksikan dengan WSC. Pita serapan tajam untuk gugus fungsi $=\mathrm{C}-\mathrm{H}$ berada pada bilangan gelombang $2930 \mathrm{~cm}^{-1}$ dan C-H antisym dan sym terjadi pada $2875 \mathrm{~cm}^{-1}$, H-bonded-OH pada $2375 \mathrm{~cm}^{-1}$, gugus fungsi-COO- antisym berada pada bilangan gelombang $1600 \mathrm{~cm}^{-1}$, dan C-O terjadi pada 1025 $\mathrm{cm}^{-1}$.
\end{abstract}

Kata kunci: hidrogel, SAP, swelling, crosslinking, WSC 


\section{PENDAHULUAN}

Penelitian tentang hidrogel yang berbasis selulosa (cellulose-basedhydrogel) telah dilakukan oleh Sannino dkk., (2006) melalui crosslinking dari campuran larutan hydroxyethylcellulose (HEC) dan carboxymethylcellulose sodium salt $(\mathrm{CMCNa})$ menggunakan water soluble carbodiimide (WSC, EDC, atau EDAC) untuk pembuatan agent pemberat dalam makanan (dietary bulking agents). Struktur kimia dari turunan selulosa dan water soluble carbodiimide (WSC) masing-masing ditunjukkan dalam Gambar 1 dan Gambar 2.

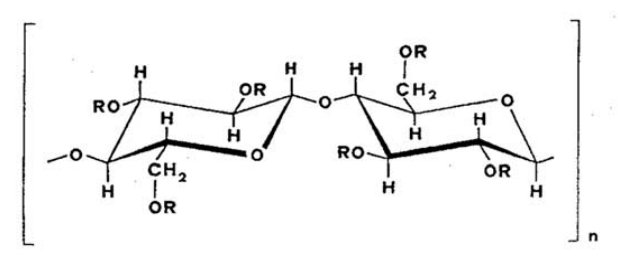

Gambar 1. Satuan Pengulangan (Repeating Unit) dari Turunan Selulosa

$\mathrm{CMCNa}, \mathrm{R}=-\mathrm{H},-\mathrm{CH}_{2} \mathrm{COONa}$

HEC, $\mathrm{R}=-\mathrm{H}, \mathrm{CH}_{2} \mathrm{CH}_{2} \mathrm{OH},-\mathrm{CH}_{2} \mathrm{CH}_{2} \mathrm{OCH}_{2} \mathrm{CH}_{2} \mathrm{OH}$, $-\mathrm{CH}_{2} \mathrm{CH}_{2} \mathrm{OCH}_{2} \mathrm{CH}_{2} \mathrm{OCH}_{2} \mathrm{CH}_{2} \mathrm{OCH}_{2} \mathrm{CH}_{2} \mathrm{OH}$.<smiles>CCN=C=NCCCN(C)C</smiles>

1-Ethyl-3-(3-dimethylaminopropyl)carbodiimide

Gambar 2. Molekul WSC, sebagai Crosslinking Agent untuk Turunan Selulosa

Dalam penelitian sebelumnya Sannino dkk., (2003 dan 2004) menyatakan bahwa keberadaan polielektrolit dari $\mathrm{CMCNa}$ adalah signifikan dalam meningkatkan kapasitas swelling hidrogel saat dibandingkan dengan hidrogel dari HEC murni, karena polielektrolit $\mathrm{CMCNa}$ adalah alami. Kenyataan tersebut menyebabkan timbulnya pengaruh Donnan (Donnan type effect) yang menimbulkan tekanan osmotik yaitu dorongan air menembus hidrogel dan selanjutnya pada proses pengeringan dengan aseton (phase inversion) menghasilkan pembentukan struktur mikroporos didalam material. Akibatnya meningkatkan kesetimbangan kapasitas swelling dan kecepatan respon terhadap stimulus lingkungan seperti $\mathrm{pH}$, suhu, dll.

Material yang secara khas terbuat dari polimer hidrofilik yang memiliki kemampuan menyerap air dalam volume besar, membengkak dengan cepat dalam suatu fluida biologi, mengikat kuat serta tidak membuang fluida tersebut ke sekitarnya mempunyai banyak kegunaan seperti diapers dan sanitary napkins (Richard dkk., 2004). Disebutkan oleh Sannino dkk. (2003) bahwa bahan busa absorben (absorbent foam materials) utamanya diperuntukkan dalam aplikasi medik yaitu untuk kulit buatan dan kantong darah tetapi relatif mahal untuk diproduksi meskipun sifatnya dapat digunakan kembali (reusable diapers). Tingginya biaya produksi menjadikan bahan busa tidak dipandang sebagai satu-satunya bahan untuk penggunaan absorben. Dengan alasan ini, timbul kebutuhan untuk memperbaiki produksi bahan superabsorben yang berbasis pada bahan baku yang dapat diperbaharuhi (renewable raw materials). Menurut Sannino dkk. (2003), kapasitas absorpsi untuk superabsorben yang berbasis polisakarida (polysaccharide-based super absorbent) perlu diperbaiki supaya bisa memiliki daya serap (absorbency) yang sama seperti superabsorben yang dipakai saat ini. Untuk mendatang ada kebutuhan terhadap bahan superabsorben yang dijual (disposable), diproduksi dari bahan awal yang dapat diperbaharuhi, siap tersedia dan murah (heap and readily available renewable starting materials).

Ichikawa dkk., (1996) menyebutkan bahwa saat ini mayoritas superabsorben diproduksi dari polimer sintetis (akrilik) karena sangat murah, meskipun demikian keputusan lembaga dunia untuk mengamankan dan melindungi lingkungan telah mendukung gagasan untuk mengganti sebagian atau seluruhnya polimer sintetis akrilik dengan polimer yang lebih hijau seperti polimer berbasis karbohidrat (polisakarida) sebagai material organik yang dapat diperbaharui, tersedia, termurah dan melimpah.

Pengembangan hidrogel superabsorben biodegradabel berbasis pada turunan selulosa untuk optimasi sumber air dalam agrikultura, hortikultura telah dilakukan oleh Demitri dkk., (2013). Dikatakan bahwa kemampuan serap hidrogel tersebut mula-mula diminati dengan dua variabel spesifik yang berperan penting dalam lingkungan tanah (soil environment) yaitu kekuatan ionik dan $\mathrm{pH}$. Oleh karena itu evaluasi awal untuk hidrogel adalah sebagai reservoir air dalam pertanian untuk percobaan rumah hijau (green house) untuk kultivasi tanaman tomat. Hidrogel SAP digolongkan menjadi empat grup berdasarkan atas ada atau tidak adanya muatan elektrik yang 
berlokasi di dalam rantai ikatan silangnya yaitu a) non-ionik; b) ionik (termasuk anionik atau kationik); c) ampholytik (mengandung gugus asam-basa) dan d) zwitterionik yang mengandung kedua gugus anionik dan kationik [ZohuriaanMehr dkk., 2008].

Mengingat Indonesia memiliki sumber bahan baku berbasis polisakarida (selulosa) yang sangat melimpah maka tujuan dari penelitian ini adalah mempelajari pembuatan hidrogel berbasis selulosa untuk pengganti tanah sebagai media tumbuh dalam pertanian misalnya untuk tanaman hias, dll.

\section{BAHAN DAN METODE}

\section{Bahan}

Hidrogel dalam penelitian ini telah diperoleh melalui proses crosslinking dari campuran larutan $\mathrm{CMCNa}$ dan HEC menggunakan 1-ethyl-3-(3-dimethylaminopropyl) carbodiimide hydrochloride sebagai crosslinking agent dalam larutan asam. CMCNa dan WSC dibeli dari Cicc-Kanto Chemical, Co., Inc, (Japan), HEC dan asam sitrat dibeli dari Sigma Aldrich (USA). Dan hidrogel PPA komersial digunakan sebagai pembanding.

\section{Metode}

\section{Sintesa Hidrogel}

Hidrogel telah disiapkan menurut prosedur berikut. Campuran CMCNa dan HEC dilarutkan dalam air distilasi dengan pengadukan sempurna pada suhu kamar sampai diperoleh larutan homogen dan jernih. Kandungan polimer akhir adalah $3 \%$ berat dengan rasio $\mathrm{CMCNa} / \mathrm{HEC}$ adalah $1 / 1 ; 3 / 1 ; 5 / 1$ dan $10 / 1$. Campuran selulosa dengan masing-masing rasio ini setelah penambahan dan pencampuran dengan 2,5\% carbodiimide WSC sebagai crosslinking agent, ditambahkan larutan asam sitrat encer $1 \%$ sebagai katalisator supaya reaksi crosslinking segera terjadi dalam 6 jam pada kondisi atmosferik. Hasil hidrogel adalah sebagian dalam keadaan bengkak (swollen), karena itu bahan-bahan kimia yang tidak bereaksi (seperti katalisator, turunan urea yang tersubstitusi dari WSC) dibuang dari jaringan polimer (polymer network) melalui pencucian dengan air distilasi sampai kesetimbangan swelling tercapai.
Akhirnya xerogel microporous disiapkan dengan mengeringkan contoh-contoh hidrogel bengkak (swollen) menggunakan aseton melalui phase inverse (Esposito dkk., 1996; Sannino dkk., 2003). Tahap pengeringan selanjutnya adalah pada $30^{\circ} \mathrm{C}$ selama 1 jam untuk mengusir sisa aseton. Contoh hidrogel yang dikeringkan dalam udara atmosfer pada kondisi kamar telah siap untuk uji perbandingan.

\section{Uji Swelling}

Pengukuran swelling dalam air distilasi dilakukan untuk menghitung kapasitas serap hidrogel (hydrogel sorption capacity) yang dinyatakan dalam swelling ratio dan ditentukan dengan metoda tea-bag menggunakan air distilasi pada suhu $22{ }^{\circ} \mathrm{C}$ (Zhao dkk., 2005). Tea-bag terbuat dari kain nilon memiliki ukuran pori \pm 300 mesh. Berat kantong nilon kering ditimbang sebagai $\mathrm{W}_{\mathrm{n}}$ dan berat contoh hidrogel kering ditimbang sebagai $\mathrm{W}_{0}$. Kantong nilon yang telah diisi contoh hidrogel dicelupkan kedalam air distilasi pada suhu ruang pada interval waktu tertentu yaitu setiap 10 menit. Kemudian kantong nilon diangkat dan digantung disuatu tempat sambil dibiarkan menetes selama 15 menit dan setelah itu ditimbang sebagai $\mathrm{W}_{\mathrm{t}}$. Pencelupan, pengangkatan dan penimbangan dilakukan berulang-ulang selama 120 menit. Air yang terserap oleh hidrogel (water uptake) dinyatakan dalam bentuk swelling ratio $\left(\mathrm{g} \mathrm{H}_{2} \mathrm{O} / \mathrm{g}\right.$ contoh hidrogel kering) yang didefinisikan sebagai berikut :

$$
\text { Swelling Ratio }(\mathrm{g} / \mathrm{g})=\left(\mathrm{W}_{\mathrm{t}}-\mathrm{W}_{0}-\mathrm{W}_{\mathrm{n}}\right) / \mathrm{W}_{0} \ldots \ldots \text { (1) }
$$

Semua pengukuran dilakukan menggunakan electronic microbalance (Adam AAA 250 L) dengan ketelitian $\pm 10^{-4} \mathrm{~g}$.

\section{Uji Deswelling}

Struktur gel yang dibentuk oleh superabsorbent polymer (SAP) yang telah menyerap air dapat mengalami kerusakan ketika kondisinya diubah secara ekstrim misalnya SAP diletakkan pada suhu yang cukup tinggi. Pengukuran deswelling dilakukan pada water bath yang suhunya diatur pada $60^{\circ} \mathrm{C}$ (Xue dkk., 2004). Hidrogel yang telah menyerap air dalam kantong nilon digantung di ruangan pada suhu $22^{\circ} \mathrm{C}$ selama 15 menit, kemudian berat hidrogel 
awal pada suhu $22^{\circ} \mathrm{C}$ ini ditimbang sebagai $m_{e}$. Kemudian kantong nilon ini dicelupkan ke dalam water bath pada suhu konstan $60^{\circ} \mathrm{C}$ selama 10 menit. Setelah itu diangkat dan digantung pada ruangan selama 15 menit lalu kantong nilon berisi SAP ini ditimbang sebagai $m_{t}$. Retensi air dalam gel dihitung sebagai $\mathrm{Wr}(\%)$ dengan persamaan berikut :

$\mathrm{Wr}=\left(\mathrm{m}_{\mathrm{t}} / \mathrm{m}_{\mathrm{e}}\right) \times 100 \%$

\section{Uji Gugus Fungsi}

Untuk melihat gugus fungsi yang terjadi pada SAP hidrogel, dilakukan analisis FTIR (Fourier Transform Infra Red) menggunakan Spectrophotometer Shimadzu.

\section{HASIL DAN PEMBAHASAN}

\section{Crosslinking Hidrogel}

Dinyatakan oleh Tomihata dkk. (1997); Nakajima dkk. (1995); Choi dkk. (1999); Park dkk. (2002); Xu dkk. (2003); Tomihata dan Ikada (1997) bahwa penggunaan water soluble carbodiimide sebagai crosslinking agent karena kemampuannya dalam mewujudkan crosslinking pada polisakarida dan memberikan perbaikan yang potensial pada biokompatibilitas hidrogel yang dihasilkan. Disamping itu molekul WSC secara kimia tidak mengikat molekul polisakarida tetapi menjadi perantara pembentukan ikatan ester antara grup karboksil dan hidroksil yang dimiliki oleh molekul polisakarida yang berbeda. WSC dapat diperoleh sebagai produk samping dari reaksi dalam bentuk turunan urea dengan derajat sitotoksisitas sangat rendah dan dapat dicuci dari jaringan polimer (polymeric network). Dengan demikian WSC dipandang sebagai crosslinking agent yang tidak beracun.

Skema reaksi WSC dengan molekul polisakarida disajikan pada Gambar 3 dengan uraian sebagai berikut : Pertama keberadaan WSC menyebabkan pembentukan intramolekuler atau intermolekuler pada asam anhidrida antara dua gugus karboksil, WSC sendiri berubah menjadi turunan urea; anhidrida ini kemudian bereaksi dengan grup hidroksil menghasilkan ikatan ester antara dua molekul polisakarida. Karena asam anhidrida tidak stabil dalam larutan air pada suhu ruang maka reaksi tidak dapat berlangsung jika gugus hidroksil tidak segera menjumpai asam anhidrida. Karena itu reaksi crosslinking dipengaruhi oleh komposisi kimia dari larutan polimer awal, dan reaksi awal WSC dengan gugus karboksil tergantung pada $\mathrm{pH}$ yaitu pH optimal berada pada rentang antara 3,5-4,5.

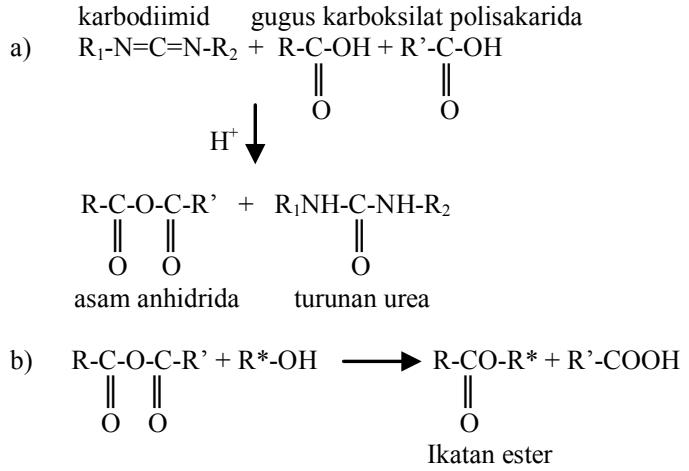

Gambar 3. Skema Reaksi WSC dengan Molekul

\section{Swelling dan Deswelling}

Gambar 4 menunjukkan empat tipe hidrogel yang telah disintesa dari campuran larutan $\mathrm{CMCNa}$ dan HEC dengan konsentrasi $3 \%$ berat dalam rasio yang berbeda yaitu $\mathrm{CMCNa} / \mathrm{HEC}=$ $1: 1 ; 3: 1 ; 5: 1$ dan $10: 1$.

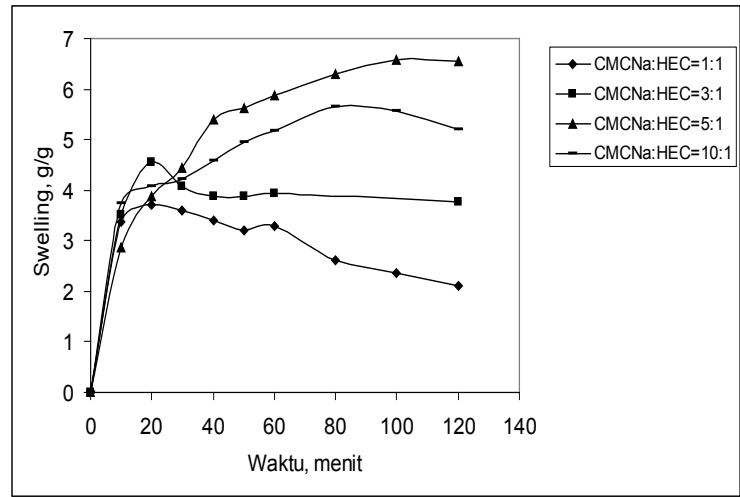

Gambar 4. Swelling Ratio dalam Air terhadap Waktu pada Variasi Perbandingan Selulosa dari Contoh Hidrogel

Dalam Gambar 4 terlihat bahwa banyaknya air yang dapat diserap (water uptake) oleh hidrogel meningkat tajam dalam 20 menit pertama untuk semua rasio, kemudian sedikit menurun lalu konstan mulai menit ke 40 untuk $\mathrm{CMCNa} /$ $\mathrm{HEC}=3: 1$. Pada $\mathrm{CMCNa} / \mathrm{HEC}=1: 1$ setelah 20 menit cenderung menurun, sedangkan untuk $\mathrm{CMCNa} / \mathrm{HEC}=10: 1$ setelah 20 menit, swelling masih bertambah sampai 80 menit dan setelah itu 
menurun. Pada rasio $\mathrm{CMCNa} / \mathrm{HEC}=5: 1$ setelah 20 menit, swelling masih bertambah sampai 100 menit dan setelah itu terlihat konstan dan rasio $\mathrm{CMCNa} / \mathrm{HEC}=5: 1$ tersebut yang menunjukkan swelling tertinggi rata-rata $6,58 \mathrm{~g} \mathrm{H}_{2} \mathrm{O} / \mathrm{g}$ hidrogel kering pada waktu 100 menit. Ketika hidrogel dalam keadaan membengkak atau swollen, rantai-rantai polimernya memisah yang luasnya ditentukan oleh sifat dari pelarut dimana hidrogel ditempatkan. Pada keadaan tertentu, rantai-rantai polimer akan memisah seluas mungkin dan interaksi kecil akan berlangsung diantara rantairantai polimer. Gambar 5 adalah kurva deswelling dari hidrogel pada rasio $\mathrm{CMC} / \mathrm{HEC}=1: 1 ; 3: 1$; 5:1 dan 10:1.

Dalam Gambar 5 terlihat bahwa pada 10 menit pertama terlihat untuk semua rasio deswelling meningkat tajam, setelah itu cenderung menurun untuk ketiga rasio yaitu $\mathrm{CMCNa} / \mathrm{HEC}=1: 1 ; 3: 1$ dan 5:1. Tetapi untuk rasio $\mathrm{CMCNa} / \mathrm{HEC}=10: 1$ setelah 10 menit deswelling sedikit bertambah dan konstan pada 100 menit, dengan retensi air dalam gel rata-rata $118 \%$. Ketika hidrogel dalam keadaan dehidrasi atau deswollen, rantai-rantai polimernya menutup rapat dengan ruang yang sempit untuk difusi molekul.

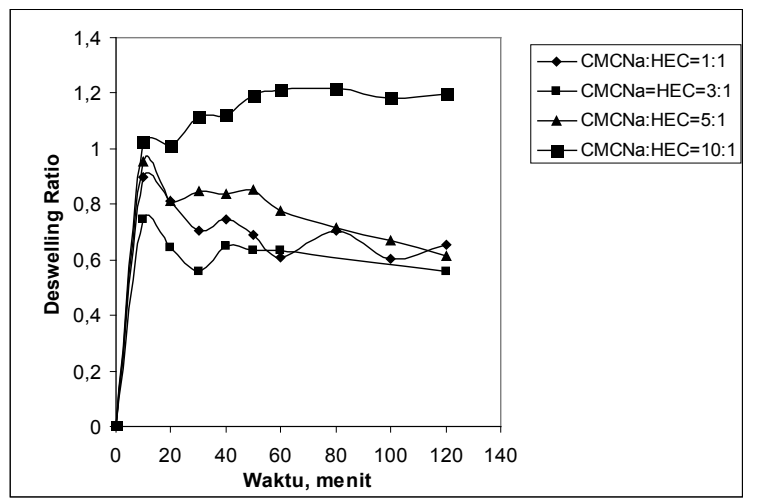

Gambar 5. Deswelling Ratio dari Contoh Hidrogel dalam Air $60^{\circ} \mathrm{C}$ terhadap Waktu

\section{Karakterisasi Gugus Fungsi}

Gambar 6 (a) adalah spektra FTIR untuk campuran $\mathrm{CMCNa}$ dan $\mathrm{HEC}$ yang tidak ditambahkan WSC dan Gambar 6 (b) adalah spektra FTIR untuk campuran CMCNa dan HEC yang ditambahkan WSC sebagai crosslinking agent. Analisis spektra FTIR dilakukan pada daerah $4000 \mathrm{~cm}^{-1}$ sampai $500 \mathrm{~cm}^{-1}$. Pada Gambar 6 (a) dan Gambar 6 (b) terlihat ada perbedaan nyata pada daerah antara $3000-2750 \mathrm{~cm}^{-1}$ dan daerah antara $1250-1000 \mathrm{~cm}^{-1}$. Tabel 1 berikut menjelaskan gugus fungsi yang terjadi setelah proses crosslinking.

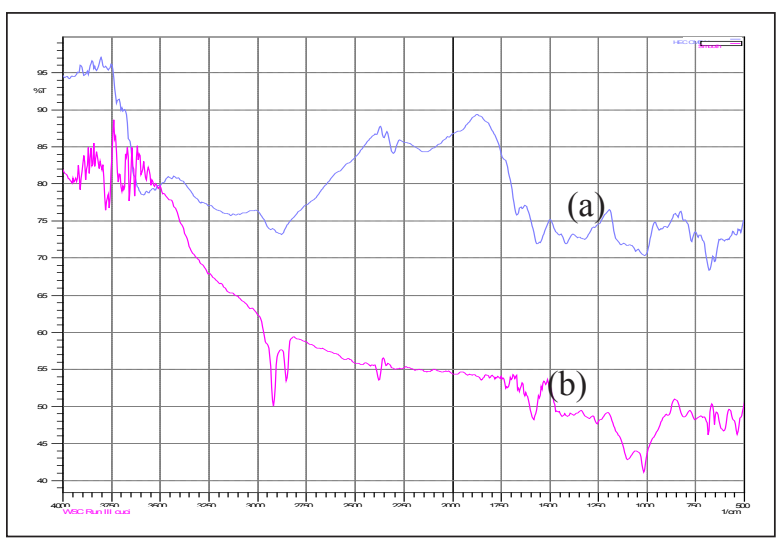

Gambar 6. Spektra FTIR dari Proses Crosslinking:

(a) Bahan Awal Campuran CMCNa dan HEC (b) Contoh Hidrogel Hasil Penelitian

Tabel 1. Karakteristik Pita Serapan dari Analisis FTIR

\begin{tabular}{|c|c|}
\hline $\begin{array}{c}\text { Bilangan } \\
\text { Gelombang, } \mathrm{cm}^{-1}\end{array}$ & Gugus Fungsi yang Terjadi \\
\hline 2930 & $=\mathrm{C}-\mathrm{H}$ stretch \\
\hline 2875 & $\begin{array}{c}\text {-C-H antisym dan sym } \\
\text { stretching }\end{array}$ \\
\hline 2375 & $\begin{array}{c}\mathrm{H}-\text { bonded -O-H stretch (solid } \\
\text { and liquid state) }\end{array}$ \\
\hline 1600 & $-\mathrm{C}^{-} \mathrm{O}$ antisym stretch \\
\hline 1025 & C-O- stretch \\
\hline
\end{tabular}

Sumber : Lin-Vien dkk., 1991

\section{KESIMPULAN}

Hidrogel berbasis selulosa dari campuran larutan $\mathrm{CMCNa}$ dan $\mathrm{HEC}$ telah disintesa menggunakan WSC sebagai crosslinking agent yang tidak toksik. Hasil hidrogel ini bersifat biodegradable, biokompatibel, aman dan ramah lingkungan. Konsentrasi selulosa pada rasio $\mathrm{CMCNa} / \mathrm{HEC}=5: 1$ memberikan derajat swelling tertinggi $6,58 \mathrm{~g} / \mathrm{g}$. Hidrogel PPA absorb komersial digunakan sebagai standar dengan derajat swelling $123 \mathrm{~g} / \mathrm{g}$. Terjadinya proses crosslinking dibuktikan pada analisis FTIR dengan munculnya gugus fungsi $=\mathrm{C}-\mathrm{H}$ - pada bilangan gelombang $2930 \mathrm{~cm}^{-1}$, dan gugus fungsi -C-H pada bilangan gelombang $2875 \mathrm{~cm}^{-1}$, 
gugus fungsi $\mathrm{H}$-bonded-O-H pada $2375 \mathrm{~cm}^{-}$ 1 , gugus fungsi - COO- antisym pada bilangan gelombang $1600 \mathrm{~cm}^{-1}$, dan $-\mathrm{C}-\mathrm{O}$ - pada bilangan gelombang $1025 \mathrm{~cm}^{-1}$.

\section{UCAPAN TERIMAKASIH}

Penelitian ini dibiayai dari kegiatan tematik DIPA Pusat Penelitian Kimia - LIPI dengan judul kegiatan "Pembuatan Material Baru Hidrogel Penyerap Air Berbasis Biopolimer untuk Media".

\section{DAFTAR PUSTAKA}

Choi, Y.S., Hong, S.R., Lee, Y.M., Song, K.W., Park, M.H., Nam, Y.S., 2002, Study on gelatin-containing artificial skin: I. Preparation and characteristics of novel gelatin-alginate sponge, Biomaterials, 20(5), $409-417$

Dimitri, C., Scalera, F., Madaghiele, M., Sannino, A., and Maffezzoli, A. 2013, Potential of Cellulose-Based Superabsorbent Hydrogels as Water Reservoir in Agriculture, International Journal of Polymer Science, 2013, $1-6$

Esposito, F.; Del Nobile, M.A.; Mensitieri, G.; and Nicolais, L., 1996, Water Sorption in Cellulose-Based Hydrogels, Journal of Applied Polymer Science, 60, 2403 - 2407.

Ichikawa T, Nakajima T, 1996, Superabsorptive Polymers (from natural polysaceharides and polypeptides), In: Polymeric Materials Encyclopedia, Salamone (Ed), CRC, Boca Raton (Florida), 8051-8059

Lin-Vien, D.; Colthup, N.; Fateley, W.G.; Grasselli, J.G., 1991, The Handbook of Infrared And Raman Characteristic Frequencies of Organic Molecules. United Kingdom Edition Published by Academic Press Limited. 24-28 Oval Road, London NWI 7DX.

Nakajima, N., Ikada, Y., 1995, Mechanism of Amide Formation by Carbodiimide for Bioconjugation in Aqueous Media, Bioconjugate Chem., 6(1), 123 - 130

Park, S.N, Park, J.C., Kim, H.O., Song, M.J., Suh, H., 2002, Characterization of porous collagen/hyaluronic acid scaffold modified by 1-ethyl-3-(3-dimethylaminopropyl) carbodiimide cross-linking, Biomaterials, $23,1205-1212$
Richard, A.G.; Guo, C. Book fm by CRC Press LLC, 2004, Section 108, 245

Sannino, A., Madaghiele, M., Lionetto, M.G., Schettino, T., Maffezzoli, A., 2006, A cellulose-based hydrogel as a potential bulking agent for hypocaloric diets: An in vitro biocompatibility study on rat intestine, Journal of Applied Polymer Science, 102 (2), 1524-1530

Sannino, A., Esposito, A., De Rosa, A., Cozzolino, A., Ambrosio, I., Nicolais, I., 2003, Biomedical application of a superabsorbent hydrogel for body water elimination in the treatment of edemas, Journal Biomed Mater Res, 67 (3), 1016 - 1024

Sannino, A, Mensitieri, G, Esposito, Nobile, M.D., 2003, Absorbent polymer material based on renewable starting materials, United State Patent 6630422

Sannino, A., Madaghiele, M., Conversano, F., Mele, G., Maffezzoli, A., Netti, PA, 2004, Cellulose Derivative-Hyaluronic AcidBased Microporous Hydrogels Cross-Linked hrough Divinylsulfone (DVS) To Modulate Equilibrium Sorption and Network Stability, Biomacromolecules, 5 (1), 92-96

Tomihata, K., Ikada, Y., 1997, Crosslinking of hyaluronic acid with water-soluble carbodiimide. Journal of Biomedical Materials Research, 37(2), 243-251

Tomihata, K; Ikada, Y. 1997, Crosslinking of hyaluronic acid with water-soluble carbodiimide, Journal Biomed Mater Res, 37 (2), 243 - 251

Xu, J.B., Bartley, J.P., Johnson, R.A, 2003, Preparation and characterization of alginatecarrageenan hydrogel films crosslinked using a water soluble carbodiimide (WSC), Journal Membran Science, 218, 131 - 146

Xue, W., Cham, S., Huglin, M.B., Jones, T.G.J., 2004, Rapid Swelling And Deswelling in Cryogels of Crosslinked Poly(Nisopropylacrylamide-co-acrylic acid), European Polymer Journal, 40 (3), 467 476

Zhao, Y., su, H.J., Fang, L., Tan, T.W., 2005, Superabsorbent hydrogels from poly(aspartic acid) with salt-, temperature- and $\mathrm{pH}-$ responsiveness properties. Polymer, 46(14), $5368-5376$

Zohuriaan-Mehr, M.J, Kabiri, K., 2008, Superabsorbent Polymer Materials: A Review, Iranian Polymer Journal, 17(6), 451-477 